\title{
Errors induced by different approximations in handling horizontal atmospheric inhomogeneities in MIPAS/ENVISAT retrievals
}

\author{
Elisa Castelli ${ }^{1}$, Marco Ridolfi' ${ }^{2,6}$, Massimo Carlotti ${ }^{3}$, Björn-Martin Sinnhuber ${ }^{4}$, Oliver Kirner $^{5}$, Michael Kiefer ${ }^{4}$, and \\ Bianca Maria Dinelli ${ }^{1}$ \\ ${ }^{1}$ Istituto di Scienze dell' Atmosfera e del Clima, ISAC-CNR, Bologna, Italy \\ ${ }^{2}$ Dipartimento di Fisica e Astronomia, Universita' di Bologna, Bologna, Italy \\ ${ }^{3}$ Dipartimento di Chimica Industriale “Toso Montanari”, Universita' di Bologna, Bologna, Italy \\ ${ }^{4}$ Karlsruhe Institute of Technology, IMK-ASF, Karlsruhe, Germany \\ ${ }^{5}$ Karlsruhe Institute of Technology, Steinbuch Center for Computing, Karlsruhe, Germany \\ ${ }^{6}$ Istituto di Fisica Applicata "Nello Carrara", IFAC-CNR, Firenze, Italy \\ Correspondence to: Elisa Castelli (e.castelli@isac.cnr.it)
}

Received: 4 March 2016 - Published in Atmos. Meas. Tech. Discuss.: 27 April 2016

Revised: 6 October 2016 - Accepted: 18 October 2016 - Published: 18 November 2016

\begin{abstract}
MIPAS (Michelson Interferometer for Passive Atmospheric Sounding) is a mid-infrared limb emission sounder that operated on board the polar satellite ENVISAT from 2002 to 2012. The retrieval algorithm used by the European Space Agency to process MIPAS measurements exploits the assumption that the atmosphere is horizontally homogeneous. However, previous studies highlighted how this assumption causes significant errors on the retrieved profiles of some MIPAS target species.

In this paper we quantify the errors induced by this assumption and evaluate the performances of three different algorithms that can be used to mitigate the problem. We generate synthetic observations with a high spatial resolution atmospheric model and carry out the retrievals with four alternative methods. The first assumes horizontal homogeneity (1-D retrieval), the second includes a model of the horizontal gradient of atmospheric temperature (1-D plus temperature gradient retrieval), the third accounts for an horizontal gradient of temperature and composition (1-D plus temperature and composition gradient retrieval), while the fourth is the full two-dimensional (2-D) inversion approach.

Our results highlight that the 1-D retrieval implies errors that are significant for averages of profiles. Furthermore, for some targets (e.g. $T, \mathrm{CH}_{4}$ and $\mathrm{N}_{2} \mathrm{O}$ below $10 \mathrm{hPa}$ ) the error induced by the 1-D approximation also becomes visible in the individual retrieved profiles. The inclusion of any kind of horizontal variability model improves all the targets with
\end{abstract}

respect to the horizontal homogeneity assumption. For temperature, $\mathrm{HNO}_{3}$ and CFC-11, the inclusion of an horizontal temperature gradient leads to a significant reduction of the error. For other targets, such as $\mathrm{H}_{2} \mathrm{O}, \mathrm{O}_{3}, \mathrm{~N}_{2} \mathrm{O}, \mathrm{CH}_{4}$, the improvements due to the inclusion of an horizontal temperature gradient are minor. In these cases, the inclusion of a gradient in the target volume mixing ratio leads to significant improvements. Among all the methods tested in this work, the 2-D approach, as expected, implies the smallest errors for almost all the target parameters. This residual error of the 2-D approach is the smoothing caused by the retrieval grid, which is coarser than that of the atmospheric model.

\section{Introduction}

Satellite limb scanning spectrometers have been widely used to measure atmospheric composition and its evolution with time. In many cases the atmospheric composition is obtained from these measurements with retrieval schemes that assume a horizontally homogeneous atmosphere (the so-called onedimensional, or 1-D retrieval approach). In most of the stratosphere this assumption does not produce huge systematic errors. However, in the case of strong horizontal variability, retrieved profiles may be affected by significant error.

In order to quantify this error, we exploit synthetic observations simulated for the MIPAS (Michelson Interferometer 
for Passive Atmospheric Sounding) instrument, which operated on board the ENVISAT satellite from March 2002 to April 2012. The instrument observed the atmospheric midinfrared emission spectrum using the limb-scanning observation technique (Fischer et al., 2008). In this spectral region several minor atmospheric constituents are active, and from the inversion of the spectrum it is possible to determine their volume mixing ratio (VMR) vertical profile in the height range from 6 to $70 \mathrm{~km}$. Due to the polar orbit of ENVISAT, MIPAS measured during the daytime in the descending (DX) part of the orbit and during night-time in the ascending (AX) part. Comparing MIPAS/ENVISAT CFC11 profiles with ACE (Atmospheric Chemistry Experiment) matching measurements, Höpfner et al. (2007) discovered unrealistic differences between MIPAS nightside and dayside CFC-11 VMRs. These discrepancies were thoroughly investigated by Kiefer et al. (2010) and were attributed to the unmodelled horizontal variability of the atmosphere in the ESA Level 2 processor. Similar horizontal gradients of temperature or composition are sounded by the instrument line of sight with the opposite sign in the ascending and the descending parts of the orbit. This sign difference causes opposite systematic errors in the profiles retrieved from the measurements acquired in the ascending and descending parts of the orbits.

In order to account for the horizontal inhomogeneities of the atmosphere, tomographic inversion codes with the capability of a full two-dimensional (2-D) model were developed for MIPAS, e.g. geofit multi-target retrieval (GMTR, Carlotti et al., 2006) MIPAS Orbital Retrieval using Sequential Estimation (MORSE, Dudhia et al., 2005), 2-D retrieval code (RET2D, von Clarmann et al., 2003) and the 2-D option of the retrieval control programme (RCP, Steck et al., 2005), for SCIAMACHY (Scanning Imaging Absorption Spectrometer for Atmospheric Chartography) (Puķite et al., 2008) and for MLS (Microwave Limb Sounder) (Livesey et al., 2006). Given the complexity of the 2-D retrieval models, von Clarmann et al. (2009) and Kiefer et al. (2010) evaluated the representation of the horizontal variability of the atmosphere with a temperature $(T)$ horizontal gradient model in the MIPAS 1-D retrieval codes. However, to date, the impact of neglecting the horizontal variability of the atmosphere and the relative improvements that can be achieved including a horizontal gradient model are still to be quantified. In this study we quantify the error due to the 1-D assumption on MIPAS retrievals on the basis of synthetic observations produced with a highly resolved atmosphere $\left(1.4^{\circ}\right.$ in latitude, much finer than the MIPAS horizontal sampling of about $4^{\circ}$ ) derived from the chemistry climate model EMAC (ECHAM/MESSy Atmospheric Chemistry, Jöckel et al., 2006) and the 2-D FM (forward model internal to the GMTR system). We retrieve the atmospheric state from these synthetic observations using, alternatively, the standard GMTR algorithm and three ad-hoc modified versions of the same code. The first modified version accounts for the horizontal variability by including user-supplied a priori horizontal gradients of temperature, the second includes user-supplied gradients of atmospheric composition, while the third modified version emulates the 1-D retrieval algorithm. The differences between the retrieved and the true atmospheric state profiles provide an estimate of the error caused by the retrieval approach.

The paper is structured as follows: in Sect. 2 we describe the method used to evaluate the size of the errors implied by the different retrieval approaches. In Sect. 3 we discuss the results of our tests. Finally, the conclusions are given in Sect. 4.

\section{Method}

When analysing real measurements, the true atmospheric state is not known. For an accurate assessment of the systematic retrieval errors due to different approaches used to account for the horizontal variability, we therefore use synthetic observations based on data from a high-resolution simulation of EMAC and on a 2-D FM which is as accurate as possible. We then apply different retrieval algorithms to these observations and evaluate the errors on the basis of the differences between retrieved and reference target parameters.

\subsection{Atmospheric model}

The reference atmosphere used to produce the synthetic spectra was extracted from a high-resolution (T85 truncation, corresponding to a horizontal resolution of $\left.1.4^{\circ} \times 1.4^{\circ}\right)$ simulation of the chemistry climate model EMAC (version 1.10; Jöckel et al., 2006) for the year 2011. In the EMAC simulation, a Newtonian relaxation technique towards meteorological analyses for the prognostic variables temperature, vorticity, divergence and the surface pressure was implemented to reproduce realistic synoptic conditions. We applied this nudging technique using the ERA-Interim reanalysis (Dee et al., 2011) from the European Centre for Medium-range Weather Forecasts (ECMWF). In this EMAC simulation a comprehensive treatment of tropospheric and stratospheric chemistry was included. The model output includes temperature, pressure, geopotential height, $\mathrm{H}_{2} \mathrm{O}, \mathrm{O}_{3}, \mathrm{HNO}_{3}, \mathrm{~N}_{2} \mathrm{O}$, $\mathrm{CH}_{4}, \mathrm{NO}_{2}, \mathrm{CFC}-11, \mathrm{CFC}-12, \mathrm{~N}_{2} \mathrm{O}_{5}, \mathrm{ClONO}_{2}$ and $\mathrm{CCl}_{4}$ on 39 model levels. The geopotential height at the surface was also given and used for the conversion to geometric height. To investigate possible seasonal variability of the error due to horizontal variability, we selected the atmospheres for the days corresponding to the solstices and equinoxes of the year 2011. For each of these days, EMAC profiles corresponding to the geolocation of real MIPAS limb scans were extracted. In particular, we selected the geolocation of MIPAS measurements in the orbits 47349 and 47350 for 21 March, 48671 and 48672 for 21 June, 49964 and 49965 for 21 September and 51301 and 51302 for 21 December. Figure 1 shows an example of temperature, $\mathrm{O}_{3}, \mathrm{HNO}_{3}$ and $\mathrm{CH}_{4}$ EMAC distri- 

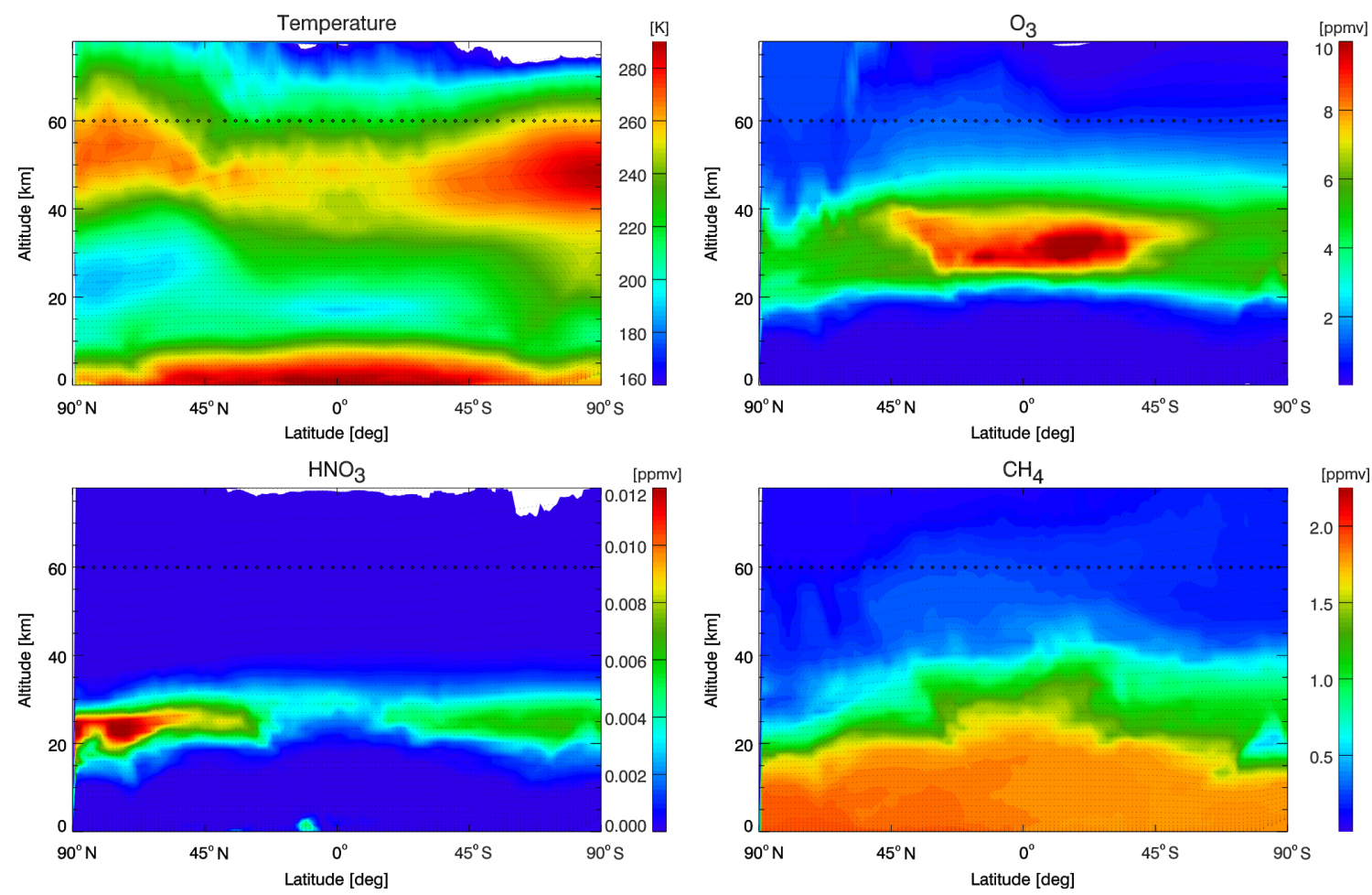

Figure 1. Temperature, $\mathrm{O}_{3}, \mathrm{HNO}_{3}$ and $\mathrm{CH}_{4}$ distributions from EMAC model simulations for 21 December 2011 as a function of altitude and latitude $\left(90^{\circ} \mathrm{N}-90^{\circ} \mathrm{S}\right)$ along MIPAS orbit 51301 . The small black dots represent EMAC altitude-latitude grid, while black diamonds represent the latitudinal position of MIPAS scans in this orbit.

bution for 21 December 2011 along MIPAS orbit 51301 . The atmospheric horizontal variability is clearly visible in Fig. 1.

The results of Kiefer et al. (2010) are based on the assumption that the average atmosphere in a given latitude band should not depend on longitude. Indeed, those averages are computed using several days of measurements allowing for an almost equal longitudinal distribution of ascending and descending profiles. Therefore, with a perfect retrieval scheme (and a constant in time atmosphere), the zonal averages of retrieved parameters should be equal when computed from measurements in the ascending or descending parts of the orbit. In the case of retrieval schemes that do not properly consider the horizontal variability, a systematic difference between the averaged ascending and the descending measurements will appear. We call this difference the "AXDX difference". In order to more clearly simulate this issue, we modified the above-mentioned reference atmospheres to make them identical in the ascending and descending parts of each orbit. If the error due to the measurement noise is sufficiently small, observed AX-DX differences in the retrieved data can, therefore, be exclusively attributed to the treatment of the horizontal variability in the retrieval.

\subsection{Synthetic observations}

The synthetic observations used in our analysis are produced with the 2-D FM internal to the GMTR code. In Kiefer et al. (2010) the authors demonstrate the capability of the GMTR code to correctly model the features of MIPAS measurements due to the horizontal variability of the atmosphere. AX-DX differences calculated from profiles retrieved with the GMTR code are very similar to those calculated with the corresponding ECMWF data. In contrast, AX-DX differences calculated from profiles derived with 1-D codes show features not present in the ECMWF data, hence they are related to an incorrect modelling of atmospheric horizontal variability. The discretisation of the atmosphere used in this FM is sufficiently fine $\left(1.4^{\circ}\right)$ to accurately model the small-scale structures of the reference atmosphere (Fig. 1) described in Sect. 2.1.

In order to focus our analysis on the error caused solely by the approximations in modelling the horizontal variability of temperature and the target gas, we modified the reference atmosphere for the generation of synthetic observations as follows: the observations used for the retrieval of the VMR of a given gas were generated assuming the 2-D distributions of the reference atmospheric model of Sect. 2.1 for both temperature and target gas. The vertical distributions of pressure and the other interfering non-target gases were set 
constant in the horizontal domain, equal to the profiles of the reference model at $\approx 45^{\circ} \mathrm{N}$ latitude. Further tests on simulated and real data (not shown) demonstrate that the pressure horizontal gradient has an almost negligible effect on 1-D retrievals. For this reason, in this study we set the pressure profiles to be latitudinally constant to better isolate the error due to the 1-D assumption on the other targets. Similarly, the observations used for the joint retrieval of pressure and temperature ( $\mathrm{pT}$ retrieval) were generated assuming the 2-D temperature distribution of the reference atmospheric model of Sect. 2.1, while the profiles of pressure and the VMR of all atmospheric species were forced to be constant in the horizontal domain, equal to the profiles of the reference model at $\approx 45^{\circ} \mathrm{N}$ latitude. As shown in Sect. 3, this approach implies equivalent AX-DX to those obtained from real MIPAS retrievals. This is due to the fact that in the GMTR retrieval system (a) the hydrostatic balance is not imposed, (b) the pressure is retrieved and (c) the pressure is used as the vertical coordinate for profile representation.

From previous studies (mentioned in Sect. 1) we know that the size of the error induced by the 1-D assumption in MIPAS retrievals is comparable to the size of the error due to measurement noise. Therefore, to better highlight the error induced by the horizontal variability model we avoided the masking effect of the noise error by adding a pseudo-random noise with standard deviation much smaller (a factor of 40) than that of real MIPAS measurements to the synthetic observations. In the linear regime, averaging retrieved profiles is equivalent to retrieving a mean profile from an average spectrum with reduced noise. We use 1/40th of the nominal noise specification both to add a synthetic pseudo-random error to the simulated measurements and to define their error covariance matrix $\mathbf{S}_{y}$ in the retrieval. Due to the different discretisations in the atmosphere used to produce the synthetic observations and in the FM internal to the inversion algorithm, we find that convergence of the retrieval is much more difficult if no noise is used. On the other hand, the noise error must be significantly reduced with respect to the nominal case in order to make the horizontal model approximation the main source of error as already performed in Carlotti et al. (2013) for the evaluation of the position error on MIPAS 1-D retrievals.

\subsection{Retrieval algorithms}

We carried out the retrievals on these synthetic observations using four algorithms. All of them were based on the GMTR algorithm of Carlotti et al. (2006).

The four algorithms, however, differ in modelling the horizontal variability of the atmosphere. In the 1-D algorithm the atmosphere is assumed to be horizontally homogeneous, in the 1-D $+\operatorname{grad}(T)$ algorithm the atmosphere is assumed to be horizontally homogeneous but a prescribed horizontal temperature gradient is included, in the $1-\mathrm{D}+\operatorname{grad}(T, \mathrm{VMR})$ algorithm the atmosphere is assumed to be horizontally ho- mogeneous but a prescribed horizontal gradient is included for temperature and the VMR of the target species. Finally, the full 2-D atmospheric variability is modelled in the 2-D algorithm.

While in the first three retrieval methods each limb scan is processed individually with a global fit (Carlotti, 1988) approach, in the 2-D retrieval the measurements of a full orbit are simultaneously used for the retrieval of the 2-D distribution (Carlotti et al., 2006). Furthermore, while in the second and third retrieval methods the horizontal gradients are externally provided by the user (fixed gradients), in the 2-D retrieval they are represented by the 2-D retrieved distribution.

The horizontal gradients used in the 1-D $+\operatorname{grad}(T)$ and 1$\mathrm{D}+\operatorname{grad}(T, \mathrm{VMR})$ tests are obtained from the 1-D retrieved atmosphere. Two different altitude-dependent horizontal gradients are calculated for the two portions of the line of sight before and beyond the tangent point of each limb observation. The gradients are used only in a range of $\pm 400 \mathrm{~km}$ about each tangent point. The profiles outside this region are set equal to their values at the boundaries of the region itself.

Note that, in the 2-D approach, a vertical profile was retrieved at the average position of each measured limb scan. Since the spacing between adjacent limb scans is of the order of $400 \mathrm{~km}$, it follows that the 2-D retrievals are affected by the so-called "smoothing error" due to a retrieval grid step which is coarser than the step adopted in the reference atmosphere.

The target profiles we retrieve from the synthetic observations are pressure, temperature ( $\mathrm{pT}$ joint retrieval), the VMR of $\mathrm{H}_{2} \mathrm{O}, \mathrm{O}_{3}, \mathrm{HNO}_{3}, \mathrm{~N}_{2} \mathrm{O}, \mathrm{CH}_{4}$ and CFC-11. For the assessment of the error for each target we first retrieve pT and use it in the subsequent retrieval of the VMR of the target gas under consideration. All the retrievals are performed on a fixed altitude grid coinciding with the nominal limb scan of the MIPAS mission after January 2004 (Raspollini et al., 2013). The altitudes of the grid are 72, 66, 62, 58, 54, 50, 46, 43, 40, 37, $34,31,29,27,25,23,21,19.5,18,16.5,15,13.5,12,10.5$, 9 , 7.5 and $6 \mathrm{~km}$. The retrieval analysis are operated on $3 \mathrm{~cm}^{-1}$ spectral intervals (the so-called micro-windows, MWs) containing information on the target parameters (Raspollini et al., 2013) and are the same as those used for MIPAS operational data processing with the ESA Level 2 processor Version 6.

\subsection{Quantifiers}

In order to characterise the performance of the different approaches employed to model horizontal variability, we first group the profiles resulting from synthetic retrievals $\left(\boldsymbol{x}_{\text {ret }}\right)$ in $15^{\circ}$ latitude bands, spanning the range from $90^{\circ} \mathrm{N}$ to $90^{\circ} \mathrm{S}$. The latitude bands are numbered with the index $k=$ $1, \ldots, 12$. In each latitude band $k$, we then interpolate the retrieved profiles to fixed pressure levels $i=1, \ldots, n_{p}$ and, separately for the profiles belonging to the AX and DX parts of the orbits, we calculate, for each pressure level, the following 

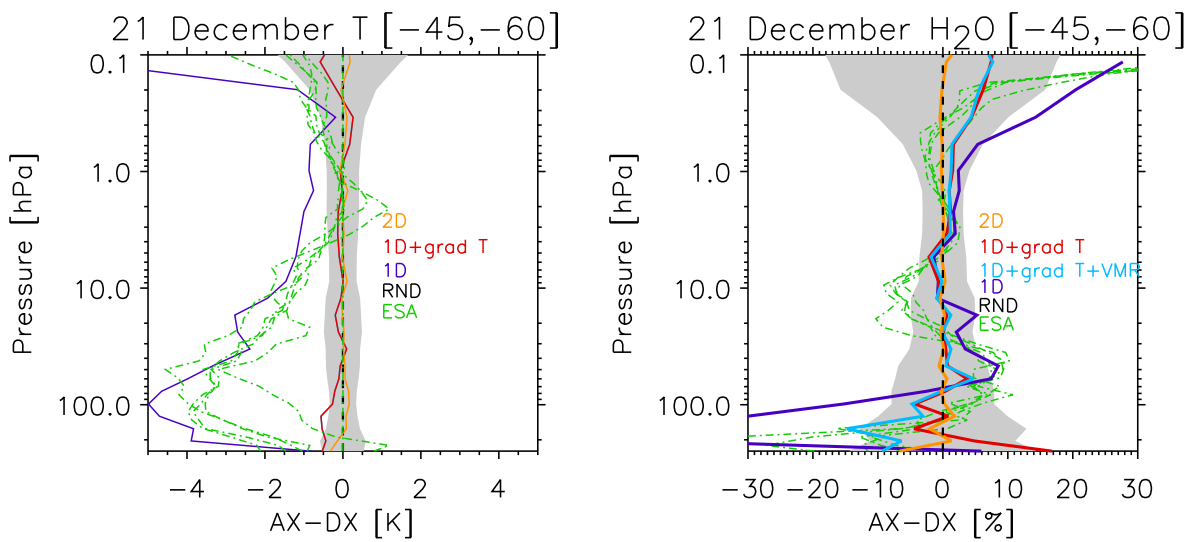

Figure 2. AX-DX differences for 21 December 2011 in the $45-60^{\circ} \mathrm{S}$ latitude band for $T$ and $\mathrm{H}_{2} \mathrm{O}$. The line colours show the differences from ESA IPF V6.0 Level 2 MIPAS data in December 2005 to 2010 in green, the 1-D retrievals in blue, the 1-D retrieval with $T$ gradients in red, the 1-D retrieval with gradients of $T$ and target species in cyan and the 2-D retrievals in orange. The grey shadow represents the average ORM (optimised retrieval model) random error (RND).
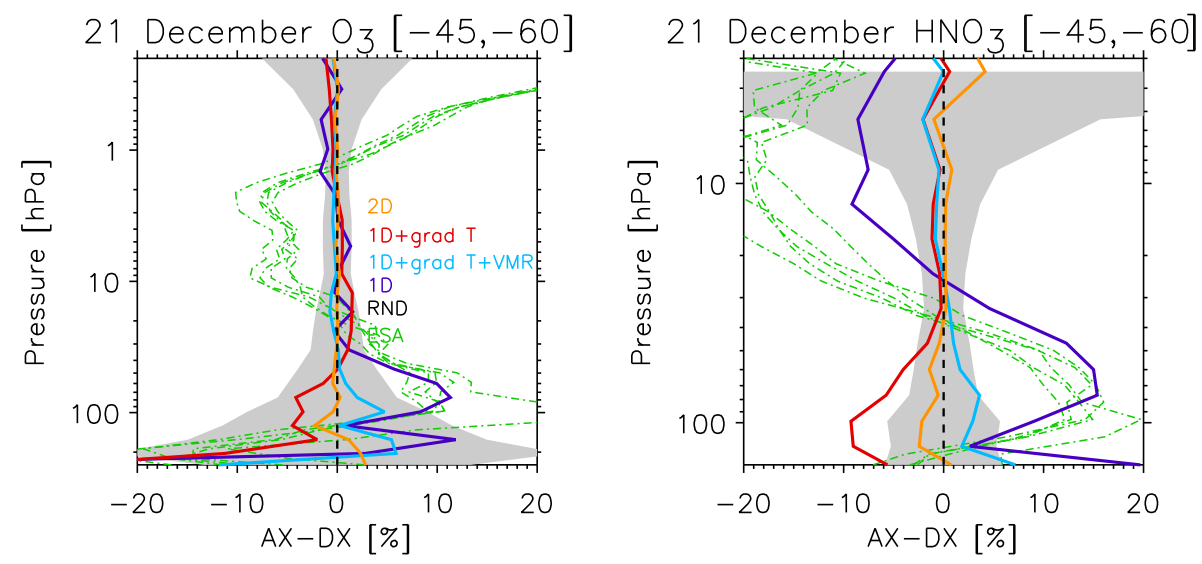

Figure 3. AX-DX differences for 21 December 2011 in the $45-60^{\circ} \mathrm{S}$ latitude band for $\mathrm{O}_{3}$ and $\mathrm{HNO}_{3}$. The colour code is the same as in Fig. 2.

quantity:

$\operatorname{diff}(i, k)=\frac{\sum_{j=1}^{n_{k}}\left(\boldsymbol{x}_{\mathrm{ret}}(i, j)-\boldsymbol{x}_{\mathrm{ref}}(i, j)\right)}{n_{k}}$,

where $j=1, \ldots, n_{k}$ numbers the retrieved $\left(\boldsymbol{x}_{\text {ret }}(i, j)\right)$ and reference $\left(\boldsymbol{x}_{\text {ref }}(i, j)\right)$ profiles within each latitude band $k$. The quantity defined in Eq. (1) represents the estimated bias, as a function of pressure and latitude band. The difference between $\operatorname{diff}(i, k)$ evaluated for the AX and DX parts of the orbits, mimics the "AX-DX difference" analysed by Kiefer et al. (2010), i.e. the most obvious artefact introduced by retrieval algorithms assuming horizontal homogeneity of the atmosphere.

In order to evaluate the performance of the horizontal variability models in different measurement conditions, we also group the results of synthetic retrievals according to the following classes: (a) from 60 to $90^{\circ} \mathrm{N}$ in December and March and latitude from 60 to $90^{\circ} \mathrm{S}$ in September and June (polar winter), (b) from 60 to $90^{\circ} \mathrm{N}$ in September and June and latitude from 60 to $90^{\circ} \mathrm{S}$ in December and March (polar summer), (c) from 60 to $30^{\circ} \mathrm{N}$ and from 60 to $30^{\circ} \mathrm{S}$, all seasons (midlatitudes), (d) from $30^{\circ} \mathrm{N}$ to $30^{\circ} \mathrm{S}$, all seasons (equatorial) and finally (e) the whole orbit class including all latitudes and seasons. For each of these classes we evaluate the root mean square error (RMSE).

\section{Results and discussion}

In Figs. 2, 3 and 4 the average AX-DX differences obtained for the December atmosphere in the $60-45^{\circ} \mathrm{S}$ latitude band for temperature and different target species are shown. In agreement with Kiefer et al. (2010), the AX-DX differences significantly deviate from zero for all the considered target species from the 1-D retrieval. Since the reference atmosphere used to generate the synthetic observations was symmetric with respect to the South Pole and the measurement 

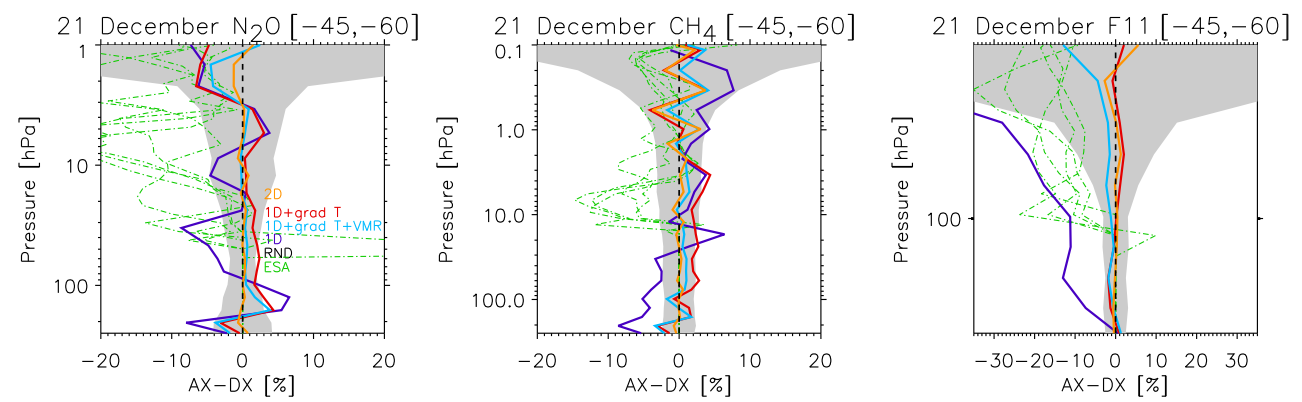

Figure 4. AX-DX differences on 21 December 2011 in the $45-60^{\circ} \mathrm{S}$ latitude band for $\mathrm{N}_{2} \mathrm{O}, \mathrm{CH}_{4}$ and $\mathrm{CFC}-11$. The colour code is the same as in Fig. 2.
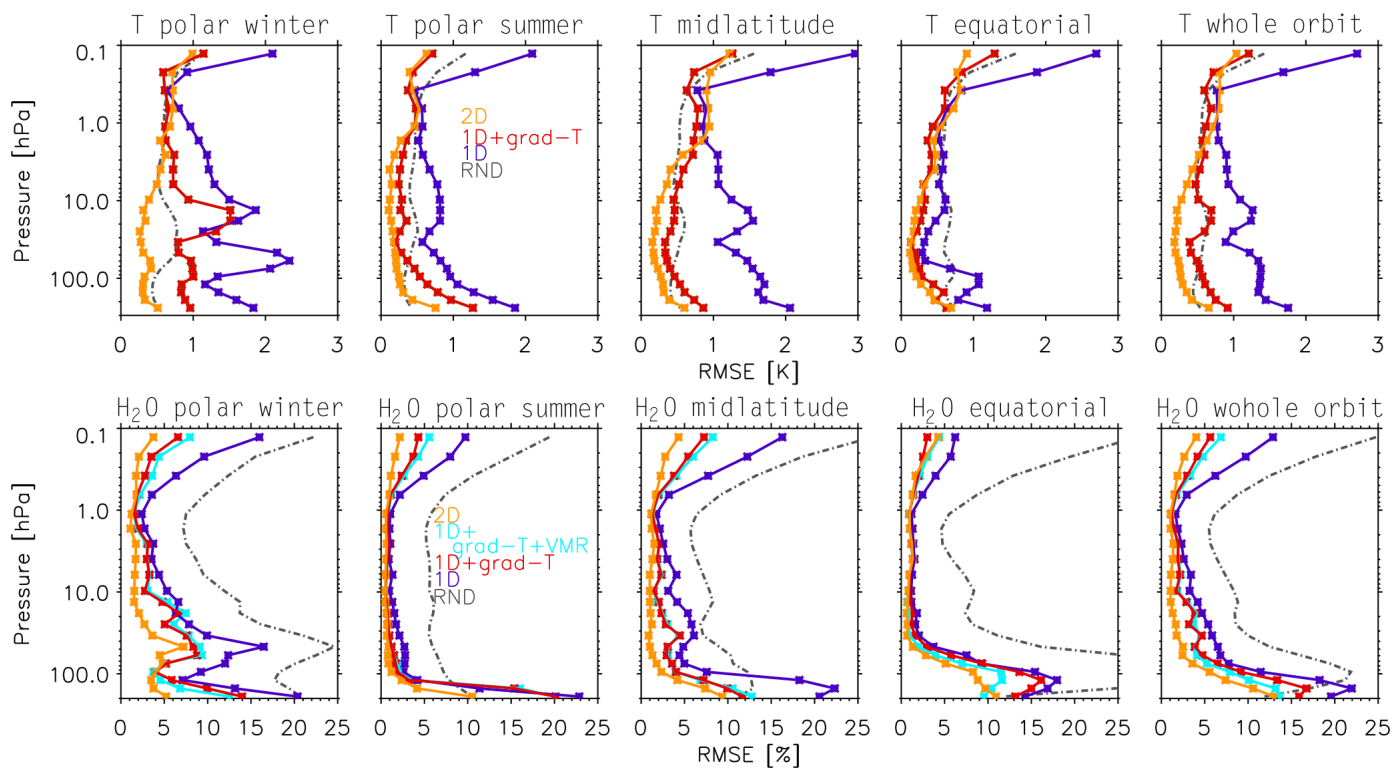

Figure 5. RMSE (root mean square error) calculations for temperature (upper panels) and $\mathrm{H}_{2} \mathrm{O}$ (lower panels) in polar winter, polar summer, midlatitude, equatorial and whole orbit scenarios. Blue for 1-D, red for 1-D + grad $(T)$, cyan for 1-D $+\operatorname{grad}(T, \mathrm{VMR})$ and orange for 2-D. Grey line represents the average ORM random error (RND).

noise was very small, the observed differences can only be ascribed to the biases introduced by neglecting the horizontal variability of the atmosphere in 1-D retrievals. For comparison purposes, in the same figures we show the values of AXDX differences calculated from the ESA IPF V6.0 Level 2 MIPAS data of December 2005 to 2010. Simulated 1-D retrievals and real measurements show very similar behaviour for most of the target species in the altitude range in which ESA AX-DX differences are available, despite the fact that different years are used. The amplitude of the 1-D AX-DX differences is comparable to that of real data, confirming the fact that the simulated observations used in our tests are suitable for reproducing the behaviour of real MIPAS measurements. The same figures show the AX-DX differences obtained with the $1-\mathrm{D}+\operatorname{grad}(T)$ retrieval, the $1-\mathrm{D}+\operatorname{grad}$ retrieval and the 2-D retrieval. We see in these figures that the introduction of a model for horizontal temperature gradients already significantly reduces the observed AX-DX differences in temperature, $\mathrm{HNO}_{3}$ and CFC-11. This result is in good agreement with the results of Fig. 17 of Kiefer et al. (2010), which refer to an average of 9 days of MIPAS measurements in January 2003, in the same latitude band. The AX-DX differences we found in case of both the 1-D and the 1-D $+\operatorname{grad}(T)$ approaches are very similar to those by Kiefer et al. (2010). This similarity holds despite the fact that our test case and the one by Kiefer et al. (2010) differs in several aspects. For example (a) we use simulated instead of real data, (b) we consider different years and months and (c) we use horizontal gradients obtained from a previous 1-D retrieval while Kiefer et al. (2010) uses gradients obtained from ECMWF re-analysis. This result suggests that the observed AX-DX differences depend mainly on the actual amplitude of the horizontal gradients, which in turn, depends mainly on season. 

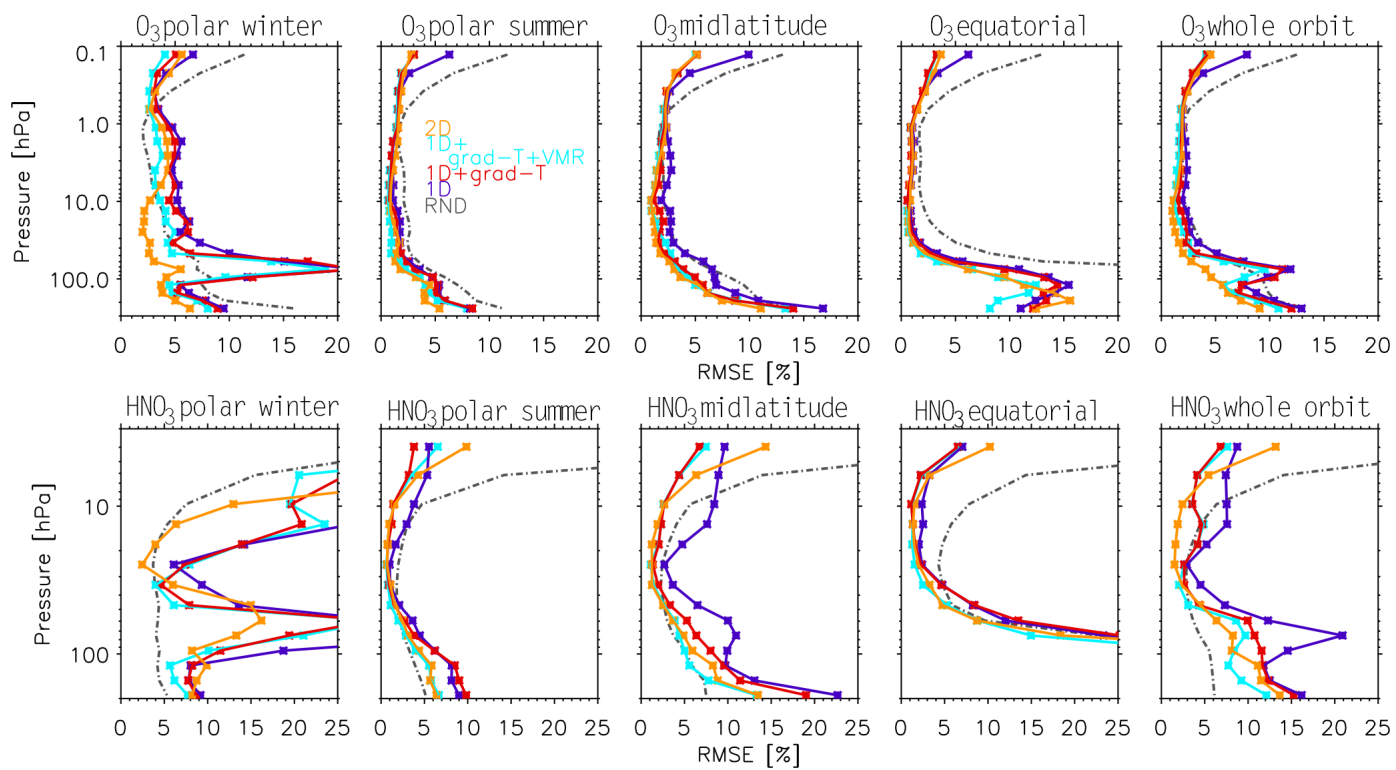

Figure 6. RMSE calculations for $\mathrm{O}_{3}$ (upper panels) and $\mathrm{HNO}_{3}$ (lower panels) in polar winter, polar summer, midlatitude, equatorial and whole orbit scenarios. The colour code is the same as in Fig. 5.

Table 1. Errors due to different treatments of horizontal inhomogeneities (1-D, 1-D $+\operatorname{grad}(T), 1-\mathrm{D}+\operatorname{grad}(T$, VMR), 2-D) for each target.

\begin{tabular}{lrrrr}
\hline & $1-\mathrm{D}$ & $1-\mathrm{D}+\operatorname{grad}(T)$ & $\begin{array}{r}1-\mathrm{D}+\operatorname{grad} \\
(T, \mathrm{VMR})\end{array}$ & $2-\mathrm{D}$ \\
\hline Temperature $[\mathrm{K}]$ & & 0.6 & - & 0.4 \\
$\mathrm{H}_{2} \mathrm{O}(0.1-70 \mathrm{hPa})[\%]$ & 1.2 & 3. & 3. & 2. \\
$\mathrm{H}_{2} \mathrm{O}(70-200 \mathrm{hPa})[\%]$ & 16. & 12. & 10. & 8. \\
$\mathrm{O}_{3}(0.1-40 \mathrm{hPa})[\%]$ & 3. & 2. & 2. & 2. \\
$\mathrm{O}_{3}(40-300 \mathrm{hPa})[\%]$ & 12. & 11. & 10. & 7. \\
$\mathrm{HNO}_{3}(3-40 \mathrm{hPa})[\%]$ & 6. & 4. & 4. & 4. \\
$\mathrm{HNO}_{3}(40-200 \mathrm{hPa})[\%]$ & 15. & 12. & 9. & 10. \\
$\mathrm{~N}_{2} \mathrm{O}[\%]$ & 6. & 5. & 4. & 4. \\
$\mathrm{CH}_{4}(0.1-10 \mathrm{hPa})[\%]$ & 5. & 4. & 3. & 3. \\
$\mathrm{CH}_{4}(10-300 \mathrm{hPa})[\%]$ & 5. & 4. & 3. & 1. \\
$\mathrm{CFC}-11(25-100 \mathrm{hPa})[\%]$ & 7. & 3. & 3. & 3. \\
$\mathrm{CFC}-11(100-300 \mathrm{hPa})[\%]$ & 3. & 2. & 3. & 2. \\
\hline
\end{tabular}

Figures 2, 3 and 4 also show that modelling the horizontal VMR gradients causes a further reduction of the AX-DX differences. Finally, 2-D retrievals produce AX-DX differences close to zero for most of the considered target species, as was already observed in Kiefer et al. (2010) using real MIPAS measurements.

Figures 5, 6 and 7 show the RMSE as a function of altitude for temperature, $\mathrm{H}_{2} \mathrm{O}, \mathrm{O}_{3}, \mathrm{HNO}_{3}, \mathrm{~N}_{2} \mathrm{O}, \mathrm{CH}_{4}$ and $\mathrm{CFC}-11$ for the different retrieval approaches. In each panel of these figures, the grey dotted-dashed line represents the average noise error for a single profile retrieval obtained in the standard Level 2 processing. This error will be referred to as "RND" and is reported in the plots to evaluate the significance of the error obtained with the different models of horizontal variability. The right panels of these figures refer to the whole orbit scenario described in Sect. 2.4, considered to provide an overall picture of the investigated model error. The averages of the RMSEs over selected pressure ranges for each target are reported in Table 1.

In the case of temperature, the 1-D method provides the largest RMSE in polar winter and midlatitude conditions and the smallest RMSE in the equatorial scenario (Fig. 5). As expected, this result correlates directly with the amplitude of the horizontal temperature gradients. The RMSE obtained for temperature in 1-D retrievals is always larger than the RND error, with the exception of the pressure range from 10 to $70 \mathrm{hPa}(\approx 19-31 \mathrm{~km})$ in the equatorial region. Over the whole orbit scenario, the RMSE averaged over the whole pressure range is about $1.2 \mathrm{~K}$. For 1-D $\mathrm{H}_{2} \mathrm{O}$ retrieval (Fig. 5) the smallest RMSE is obtained in polar summer conditions, 

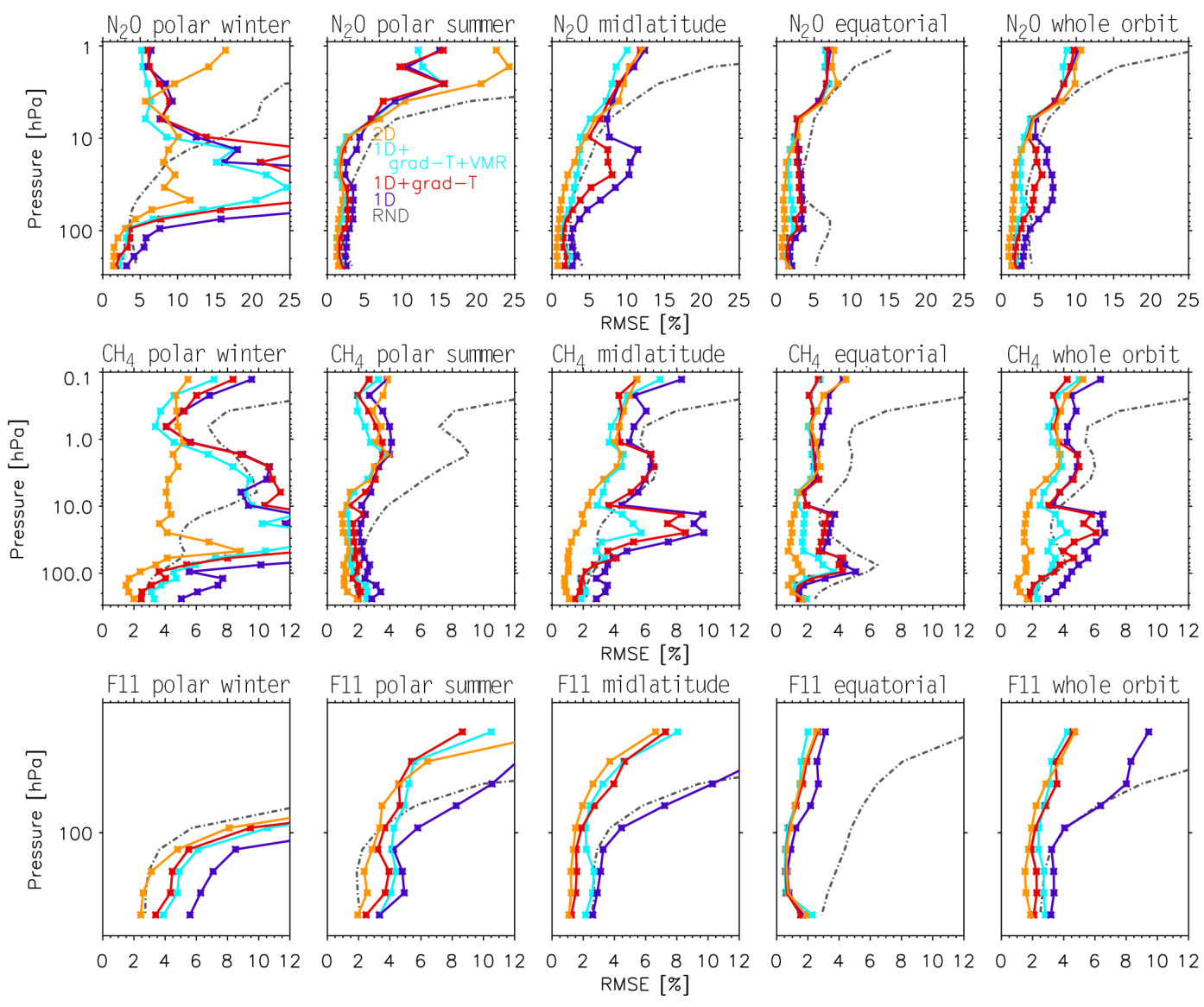

Figure 7. From top to bottom: RMSE calculations for $\mathrm{N}_{2} \mathrm{O}, \mathrm{CH}_{4}$ and $\mathrm{CFC}-11$ in polar winter, polar summer, midlatitude, equatorial and whole orbit scenarios. The colour code is the same as in Fig. 5.

and in general the RMSE is well below the RND error. Over the whole orbit scenario, the RMSE averaged over the pressure range $0.1-70 \mathrm{hPa}$ is about $5 \%$, while it is $16 \%$ in the 70-200 hPa range (see Table 1). In the case of $\mathrm{O}_{3}$ (Fig. 6), the worst results are obtained with 1-D retrievals for polar winter and midlatitude conditions (in agreement with the latitudinal behaviour of the horizontal temperature and ozone gradients) with an average RMSE over the whole orbit scenario of the same order as the RND error. RMSE calculations for 1-D $\mathrm{HNO}_{3}$ retrievals (Fig. 6) show that the largest RMSEs are obtained for polar winter and midlatitude conditions. In these cases the RMSE is larger than the RND error. A similar behaviour is observed for $\mathrm{N}_{2} \mathrm{O}$ and $\mathrm{CH}_{4}$ (Fig. 7) with an average RMSE of $5 \%$. Finally, for CFC-11 we get an average RMSE of $7 \%$ in the $25-100 \mathrm{hPa}$ region and $3 \%$ in the 100-300 $\mathrm{hPa}$ region when using the 1-D approach.

These results show that the introduction of all of the models for horizontal variability produce improvements for all the targets (Table 1). The temperature RMSEs are reduced to less than $1 \mathrm{~K}$ when horizontal gradients are modelled and to less than $0.5 \mathrm{~K}$ in the case of 2-D retrievals. $\mathrm{H}_{2} \mathrm{O}$ RMSEs can be reduced down to $3 \%$ in the $0.1-70 \mathrm{hPa}$ region and to $10 \%$ in the $70-200 \mathrm{hPa}$ region by modelling temperature and VMR gradients. When both the VMR and temperature gradients are applied, the error on $\mathrm{O}_{3}$ reduces to a few percent below $40 \mathrm{hPa}$ and above $0.2 \mathrm{hPa}$ (see Fig. 6). In the case of $\mathrm{HNO}_{3}$, both modelling of horizontal gradients and the 2-D approach mitigate the effect of horizontal variability (only few percent differences remain) over the whole altitude range. In the case of $\mathrm{N}_{2} \mathrm{O}$ and $\mathrm{CH}_{4}$, modelling the $T$ and VMR horizontal gradients and the 2-D approach greatly reduces the error, in particular in the altitude range of their peak VMRs. The CFC-11 1-D retrieval is heavily influenced by the horizontal variability with a large (around $15 \%$ ) error above $100 \mathrm{hPa}$. This error can be greatly reduced when atmospheric variability is taken into account (Figs. 4 and 7) using any of the methods described in this study.

The modelling of a temperature horizontal gradient produces a significant reduction of the error in temperature, $\mathrm{HNO}_{3}$ and CFC- $11 . \mathrm{H}_{2} \mathrm{O}$ retrievals also improve partially at high altitudes. The reduction of error is marginal for the other VMR retrievals. Modelling the horizontal VMR gradient as well produces a further reduction of the RMSE. The largest improvements are obtained in $\mathrm{O}_{3}, \mathrm{CH}_{4}$ and $\mathrm{N}_{2} \mathrm{O}$ retrievals, 
Table 2. RMSE improvements due to different treatments of horizontal inhomogeneities $(1-\mathrm{D}+\operatorname{grad}(T), 1-\mathrm{D}+\operatorname{grad}(T, \mathrm{VMR}), 2-\mathrm{D})$ for each target with respect to $1-\mathrm{D}$.

\begin{tabular}{lrrr}
\hline & $\begin{array}{r}\text { 1-D }+\operatorname{grad}(T) \\
\text { vs. 1-D }\end{array}$ & $\begin{array}{r}\text { 1-D }+ \text { grad } \\
(T, V M R)\end{array}$ & $\begin{array}{r}\text { 2-D vs. } \\
\end{array}$ \\
\hline Temperature [\%] & - & $1-\mathrm{D}$ \\
$\mathrm{H}_{2} \mathrm{O}(0.1-70 \mathrm{hPa})[\%]$ & 49 & 37 & 63 \\
$\mathrm{H}_{2} \mathrm{O}(70-200 \mathrm{hPa})[\%]$ & 38 & 37 & 49 \\
$\mathrm{O}_{3}(0.1-40 \mathrm{hPa})[\%]$ & 22 & 33 & 35 \\
$\mathrm{O}_{3}(40-300 \mathrm{hPa})[\%]$ & 27 & 19 & 44 \\
$\mathrm{HNO}_{3}(3-40 \mathrm{hPa})[\%]$ & 9 & 37 & 36 \\
$\mathrm{HNO}_{3}(40-200 \mathrm{hPa})[\%]$ & 36 & 37 & 33 \\
$\mathrm{~N}_{2} \mathrm{O}[\%]$ & 19 & 34 & 37 \\
$\mathrm{CH}_{4}(0.1-10 \mathrm{hPa})[\%]$ & 20 & 24 & 24 \\
$\mathrm{CH}_{4}(10-300 \mathrm{hPa})[\%]$ & 13 & 38 & 71 \\
$\mathrm{CFC}_{1}-11(25-100 \mathrm{hPa})[\%]$ & 25 & 57 & 57 \\
$\mathrm{CFC}-11(100-300 \mathrm{hPa})[\%]$ & 54 & 19 & 49 \\
\hline
\end{tabular}

while $\mathrm{H}_{2} \mathrm{O}$ at high altitudes and $\mathrm{CFC}-11$ benefit very little from this additional sophistication.

The RMSEs obtained with the 2-D approach, reported in the last column of Table 1, are generally smaller than those obtained with any of the simpler horizontal gradient models. Improvements given by the use of different approaches to model horizontal gradients with respect to 1-D case are summarised in Table 2.

\section{Conclusions}

In this work we quantify the error induced by neglecting the horizontal variability of the atmosphere in MIPAS retrievals and characterise possible alternative retrieval approaches that could help to reduce this error. Our study is based on synthetic limb observations generated with an accurate 2-D forward model that assumes a known atmospheric state taken from a high-resolution model (EMAC). We evaluate the relative performance of some different retrieval approaches: the simple 1-D model, the model of horizontal temperature gradients, the model of both temperature and a VMR horizontal gradients, the full 2-D model.

The results show that neglecting the horizontal atmospheric variability can produce average errors of $\approx 1.2 \mathrm{~K}$ for temperature (maximum around $2 \mathrm{~K}$ ), $5-16 \%$ for $\mathrm{H}_{2} \mathrm{O}, 3-$ $11 \%$ for $\mathrm{O}_{3}, 6-15 \%$ for $\mathrm{HNO}_{3}, 6 \%$ for $\mathrm{N}_{2} \mathrm{O}, 5 \%$ for $\mathrm{CH}_{4}$ and $7-3 \%$ for CFC-11 depending on the considered pressure range. In the cases of $T, \mathrm{CH}_{4}$ and $\mathrm{N}_{2} \mathrm{O}$ retrievals below $10 \mathrm{hPa}$, the error induced by the 1-D approximation also becomes significant compared to noise error in the individual retrieved profiles. For the other target parameters, this effect is only expected to be important for averages of profiles.

Modelling a temperature horizontal gradient improves temperature (error reduced to $0.6 \mathrm{~K}$ ), $\mathrm{HNO}_{3}$ and $\mathrm{CFC}-11$ retrievals (as already reported in Kiefer et al., 2010). The effect on the retrieval of the other considered molecules is mi- nor. As already mentioned in Carlotti et al. (2013), this is due to the fact that the 1-D retrieved temperature profiles, even if differing from the real temperature, represent "effective" profiles that partially compensate for the horizontal inhomogeneity error. Thus, modelling the horizontal temperature gradient improves the accuracy of the temperatures but only marginally the quality of some retrieved VMRs. The amplitude of this compensation effect depends on the MWs used.

Modelling both temperature and VMR gradients reduces the error to 3-10\% for $\mathrm{H}_{2} \mathrm{O}, 2-9 \%$ for $\mathrm{O}_{3}, 4-9 \%$ for $\mathrm{HNO}_{3}$, $4 \%$ for $\mathrm{N}_{2} \mathrm{O}, 3 \%$ for $\mathrm{CH}_{4}$ while no improvement is obtained for CFC-11. The improvements obtained for $\mathrm{O}_{3}, \mathrm{CH}_{4}$ and $\mathrm{N}_{2} \mathrm{O}$ are particularly important, because they are concentrated in the altitude region where the VMRs have their maximum values.

The horizontal temperature and VMR gradient values used in our tests are derived from the corresponding atmospheric fields retrieved with the 1-D assumption. We consider these gradients to be relatively accurate. We verified, however, that using less accurate gradients, such as those that can be inferred, e.g. from ECMWF analyses, usually produces a less significant reduction of the retrieval error.

The 2-D retrieval approach produces the smallest error in modelling the horizontal variability of the atmosphere. We note that the real benefits of the 2-D approach are even more evident when looking at the vertical distribution of the errors: the 2-D results always perform better than the other approaches, especially in the altitude regions and latitudinal bands where the horizontal variability is largest. The remaining error is due to the horizontal smoothing intrinsic to the measuring system. With the adopted atmospheric model, this smoothing error is of the order of $0.5 \mathrm{~K}$ for temperature, 2$8 \%$ for $\mathrm{H}_{2} \mathrm{O}, 2-7 \%$ for $\mathrm{O}_{3}, 4-10 \%$ for $\mathrm{HNO}_{3}, 4 \%$ for $\mathrm{N}_{2} \mathrm{O}$, 3-1\% for $\mathrm{CH}_{4}$ and 3-2\% for CFC-11. In the 2-D approach, all the measurements of a full orbit are simultaneously in- 
verted to infer the full 2-D distribution of the target parameter. Therefore, the 2-D approach does not need any externally supplied horizontal gradients and, for this reason, it is not prone to the systematic error that may be caused by the use of inaccurate external information.

\section{Data availability}

Data retrieved from MIPAS synthetic observations used in this study are available from the authors upon request.

Acknowledgements. This work was performed under ESA-ESRIN Contract no. 21719/08/I-OL. The authors gratefully acknowledge Richard Siddans (RAL) for proofreading the manuscript and ECMWF for access to data.

Edited by: P. K. Bhartia

Reviewed by: three anonymous referees

\section{References}

Carlotti, M.: Global-fit approach to the analysis of limbscanning atmospheric measurements, Appl. Opt., 27, 32503254, doi:10.1364/AO.27.003250, 1988.

Carlotti, M., Brizzi, G., Papandrea, E., Prevedelli, M., Ridolfi, M., Dinelli, B. M., and Magnani, L.: GMTR: Two-dimensional geofit multitarget retrieval model for Michelson Interferometer for Passive Atmospheric Sounding/Environmental Satellite observations, Appl. Opt., 45, 716-727, 2006.

Carlotti, M., Arnone, E., Castelli, E., Dinelli, B. M., and Papandrea, E.: Position error in profiles retrieved from MIPAS observations with a 1-D algorithm, Atmos. Meas. Tech., 6, 419-429, doi:10.5194/amt-6-419-2013, 2013.

Dee, D. P., Uppala, S. M., Simmons, A. J., Berrisford, P., Poli, P., Kobayashi, S., Andrae, U., Balmaseda, M. A., Balsamo, G., Bauer, P., Bechtold, P., Beljaars, A. C. M., van de Berg, L., Bidlot, J., Bormann, N., Delsol, C., Dragani, R., Fuentes, M., Geer, A. J., Haimberger, L., Healy, S. B., Hersbach, H., Hólm, E. V., Isaksen, L., Kållberg, P., Köhler, M., Matricardi, M., McNally, A. P., Monge-Sanz, B. M., Morcrette, J.-J., Park, B.-K., Peubey, C., de Rosnay, P., Tavolato, C., Thépaut, J.-N., and Vitart, F.: The ERA-Interim reanalysis: configuration and performance of the data assimilation system, Q. J. Roy. Meteor. Soc., 137, 553-597, doi:10.1002/qj.828, 2011.

Dudhia, A., Jay, V. L., and Rodgers, C. D.: MIPAS Orbital Retrieval using Sequential Estimation, Earth Observation Data Group, Department of Physics, University of Oxford, available at: http: //www.atm.ox.ac.uk/MORSE/ (last access: 14 November 2016), 2005.

Fischer, H., Birk, M., Blom, C., Carli, B., Carlotti, M., von Clarmann, T., Delbouille, L., Dudhia, A., Ehhalt, D., Endemann, M., Flaud, J. M., Gessner, R., Kleinert, A., Koopman, R., Langen, J., López-Puertas, M., Mosner, P., Nett, H., Oelhaf, H., Perron, G., Remedios, J., Ridolfi, M., Stiller, G., and Zander, R.: MIPAS: an instrument for atmospheric and climate research, Atmos. Chem. Phys., 8, 2151-2188, doi:10.5194/acp-8-2151-2008, 2008.
Höpfner, M., von Clarmann, T., Engelhardt, M., Fischer, H., Funke,B., Glatthor, N., Grabowski, U., Kellmann, S., Kiefer, M., Linden, A., López-Puertas, M., Milz, M., Steck, T., Stiller, G. P., Wang, D. Y., Ruhnke, R., Kouker, W., Reddmann, T., Bernath, P., Boone, C., and Walker, K. A.: Comparison between ACE-FTS and MIPAS IMK/IAA profiles of $\mathrm{O}_{3}, \mathrm{H}_{2} \mathrm{O}, \mathrm{N}_{2} \mathrm{O}, \mathrm{CH}_{4}$, CFC-11, CFC-12, $\mathrm{HNO}_{3}, \mathrm{ClONO}_{2}, \mathrm{NO}_{2}, \mathrm{~N}_{2} \mathrm{O}_{5}, \mathrm{CO}$, and SF6 in February/March 2004, Third Workshop on the Atmospheric Chemistry Validation of Envisat, (ACVE-3), ESRIN, Frascati, Italy, 4-7 December 2006, ESA SP-642, ESA Publications Division, ESTEC, the Netherlands, 2007.

Jöckel, P., Tost, H., Pozzer, A., Brühl, C., Buchholz, J., Ganzeveld, L., Hoor, P., Kerkweg, A., Lawrence, M. G., Sander, R., Steil, B., Stiller, G., Tanarhte, M., Taraborrelli, D., van Aardenne, J., and Lelieveld, J.: The atmospheric chemistry general circulation model ECHAM5/MESSy1: consistent simulation of ozone from the surface to the mesosphere, Atmos. Chem. Phys., 6, 50675104, doi:10.5194/acp-6-5067-2006, 2006

Livesey, N. J., Van Snyder, W., Read, W. G., and Wagner, P. A.: Retrieval algorithms for the EOS Microwave Limb Sounder (MLS), IEEE T. Geosci. Remote, 44, 1144-1155, 2006.

Kiefer, M., Arnone, E., Dudhia, A., Carlotti, M., Castelli, E., von Clarmann, T., Dinelli, B. M., Kleinert, A., Linden, A., Milz, M., Papandrea, E., and Stiller, G.: Impact of temperature field inhomogeneities on the retrieval of atmospheric species from MIPAS IR limb emission spectra, Atmos. Meas. Tech., 3, 1487-1507, doi:10.5194/amt-3-1487-2010, 2010.

Puķīte, J., Kühl, S., Deutschmann, T., Platt, U., and Wagner, T.: Accounting for the effect of horizontal gradients in limb measurements of scattered sunlight, Atmos. Chem. Phys., 8, 3045-3060, doi:10.5194/acp-8-3045-2008, 2008.

Raspollini, P., Carli, B., Carlotti, M., Ceccherini, S., Dehn, A., Dinelli, B. M., Dudhia, A., Flaud, J.-M., López-Puertas, M., Niro, F., Remedios, J. J., Ridolfi, M., Sembhi, H., Sgheri, L., and von Clarmann, T.: Ten years of MIPAS measurements with ESA Level 2 processor V6 - Part 1: Retrieval algorithm and diagnostics of the products, Atmos. Meas. Tech., 6, 2419-2439, doi:10.5194/amt-6-2419-2013, 2013.

Steck, T., Höpfner, M., von Clarmann, T., and Grabowski, U.: Tomographic retrieval of atmospheric parameter from infrared limb emission observations, Appl. Opt., 44, 3291-3301, 2005.

von Clarmann, T., Ceccherini, S., Doicu, A., Dudhia, A., Funke, B., Grabowski, U., Hilgers, S., Jay, V., Linden, A., LópezPuertas, M., Martín-Torres, J.-F., Payne, V., Reburn, J., Ridolfi, M., Schreier, F., Schwarz, G., Siddans, R., and Steck, T.: A blind test retrieval experiment for infrared limb emission spectrometry, J. Geophys. Res., 108, 4746, doi:10.1029/2003JD003835, 2003. von Clarmann, T., Höpfner, M., Kellmann, S., Linden, A., Chauhan, S., Funke, B., Grabowski, U., Glatthor, N., Kiefer, M., Schieferdecker, T., Stiller, G. P., and Versick, S.: Retrieval of temperature, $\mathrm{H}_{2} \mathrm{O}, \mathrm{O}_{3}, \mathrm{HNO}_{3}, \mathrm{CH}_{4}, \mathrm{~N}_{2} \mathrm{O}, \mathrm{ClONO}_{2}$ and $\mathrm{ClO}$ from MIPAS reduced resolution nominal mode limb emission measurements, Atmos. Meas. Tech., 2, 159-175, doi:10.5194/amt-2-159-2009, 2009. 